\title{
viewpoint
}

\section{The write position}

\author{
A survey of perceived contributions to papers based on byline position and number of authors \\ Jonathan D. Wren, Katarzyna Z. Kozak, Kathryn R. Johnson, Sara J. Deakyne, Lisa M. Schilling \\ \& Robert P. Dellavalle
}

$\mathrm{P}$ ublications in peer-reviewed journals are a major criterion for assessing scientists for promotion, tenure or funding (Beasley \& Wright, 2003; Thomas et al, 2004). Yet, there are different ways of becoming an author on a scientific publication, and not all authors are viewed as equal contributors. Qualitatively speaking, those listed first or last in the byline are generally apportioned more credit for the work than middle authors. However, exactly how much authors are perceived to contribute from their byline position is not known. Given the central role of publications in evaluating scientific productivity and the trend towards more authors per published paper (Fig 1), it is important that we gain a better quantitative understanding of these perceptions.

It is often not possible to objectively determine exactly how much credit each author on a paper deserves for the sum total of the work performed (Laurance, 2006; Tscharntke et al, 2007). Presumably, a larger number of authors dilutes the relative credit awarded to each contributor; however, this effect has not been scientifically confirmed or quantified. Yet, the number of authors per paper in PubMed is growing-so-called 'author inflation'. This is an increasing trend in many research fields largely owing to the increasing pressure to publish, specialization of research expertise, collaborative efforts and honorary authorships, also known as 'gift authorships' (Drenth, 1998; Lazar, 2004; Mussurakis, 1993; Kwok, 2005; Mowatt et al, 2002; Smith, 1994; Tarnow, 2004a). Although the International Committee of Medical Journal Editors (ICMJE; Washington, DC, USA) has formally defined authorship criteria, many researchers define authorship differently (ICMJE, 2006; Eastwood et al,

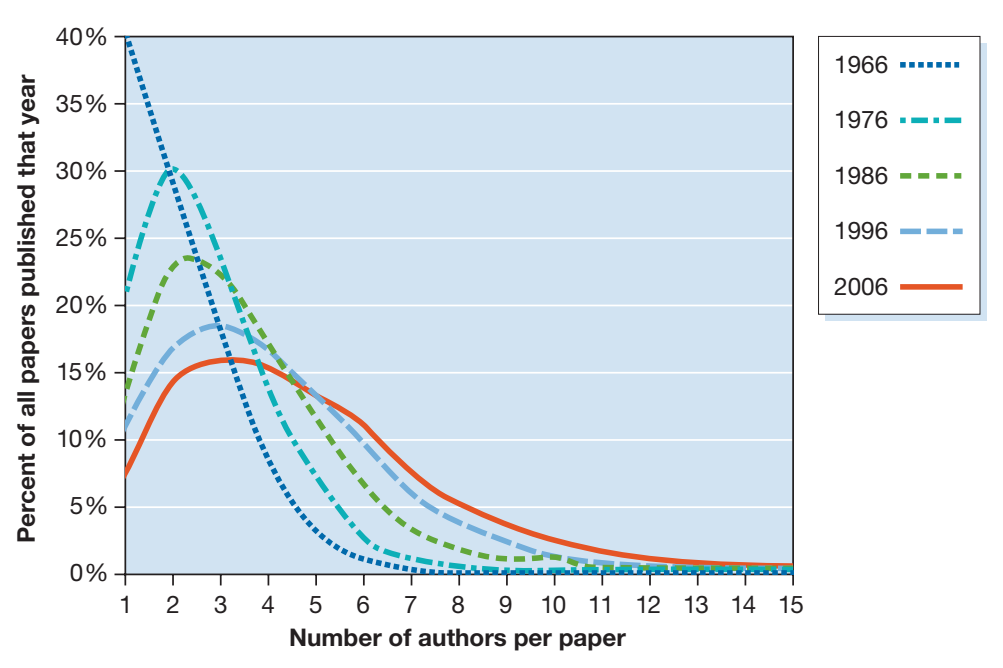

Fig 1 | Frequency distribution of the number of authors per paper by decade since 1966. The graph was generated using MEDLINE bibliographic data and truncated at 15 authors maximum. All types of publication were included in the analysis, with journal article the most common type (86\%).

1996; Tarnow, 1999). Without explicit statements about each author's contributions to the work described, readers_-including promotion committee members-implicitly apportion authorship credit and frequently do so in the absence of any well-defined standards (Tarnow, 2004b).

Most biomedical authors are aware, in an informal sense, that the first and last author positions are generally perceived as the 'key' positions on a paper; but there is no consensus on the value of other positions. Surveys of first authors have shown that their perceptions of their co-author(s)'s contributions can vary greatly between the papers they publish (Shapiro et al, 1994). The differing values of byline positions become evident in the case of 'joint first authors' or declarations that authors 'contributed equally'. Presumably, in the absence of such a statement, readers might assume that the contribution of the second author is less than it actually was.

Quantitatively, the relative importance of different byline positions is not known, nor the effect of adding new authors. In the absence of explicit information, editors and committee members often make decisions based on assumptions. Editors, for example, seeking reviewers for a paper, will search the literature for authors publishing similar papers and invite them as a reviewer on the basis of their perceived expertise. Yet, the literature often does not contain any more 
information than the byline for making such a decision. In these cases, misperceptions of deserved credit will not have a direct impact on the authors; although in others, such as when a faculty candidate is being evaluated for promotion or tenure, misperceptions can have direct and tangible consequences. Thus, all authors will benefit from a better and more quantitative understanding of how their contributions are likely to be perceived by their peers.

A gainst this background, we conducted a survey of promotion and tenure committee chairpeople to assess their perceptions of author contributions based on an author's byline position and the total number of authors on a paper; and how such perceptions might have an impact on the decisions they make. We designed an 18-question survey that used multiple-choice, a 5-point Likert scale, percentage scale and fill-in question formats (see supplementary information online).

We assessed three types of authorship credit category: initial conception (IC) of a project, work performed (WP) and supervision (S) of the project. Overall author credit was calculated as the mean of the percentages assigned to the three individual author credit categories. Three specific questions asked the respondents to apportion credit based on an author's position in the byline. To determine whether an increasing number of authors affected an individual's share of the credit, respondents were asked to apportion credit for threeauthor and five-author bylines, with the last author being designated as the corresponding author. To determine the effect of the corresponding-author position, the survey asked respondents to repeat the five-author evaluation, with the middle author designated as corresponding author instead of the last author.

The questionnaires were mailed to promotion committees at all medical schools accredited by the Association of American Medical Colleges (AAMC; Washington, DC, USA). AAMC represents the 125 medical schools in the USA and Puerto Rico, and the 17 Canadian medical schools that grant a medical doctorate. Up to three surveys were sent to each medical school between September and November 2005, separated by six-week periods. The answers were anonymized, entered into a password-protected database and analysed using SAS Version 9 (Cary, NC, USA).

Table 1 | Perceived credit per author by their byline position on a hypothetical manuscript, divided into separate categories of contribution

\begin{tabular}{|c|c|c|c|c|}
\hline $\begin{array}{l}\text { Author } \\
\text { position }\end{array}$ & Initial conception & Work performed & Supervision & Mean \\
\hline \multicolumn{5}{|c|}{ Three-author paper (last author as the corresponding author) } \\
\hline First & $37 \pm 16(35)$ & $57 \pm 15(60)$ & $33 \pm 23(30)$ & $42 \pm 13$ \\
\hline Second & - & - & - & - \\
\hline Middle & $14 \pm 10(10)$ & $23 \pm 10(20)$ & $13 \pm 12(10)$ & $17 \pm 6$ \\
\hline Fourth & - & - & - & - \\
\hline Last $^{*}$ & $49 \pm 21(50)$ & $20 \pm 13(20)$ & $54 \pm 28(50)$ & $41 \pm 19$ \\
\hline
\end{tabular}

Five-author paper (last author as the corresponding author) ${ }^{a}$

\begin{tabular}{lllll}
\hline First & $29 \pm 16(p \leq 0.004)(30)$ & $46 \pm 17(p \leq 0.001)(50)$ & $29 \pm 20(p \leq 0.29)(22.5)$ & $34 \pm 14$ \\
\hline Second & $10 \pm 8(10)$ & $16 \pm 7(20)$ & $9 \pm 7(10)$ & $12 \pm 10$ \\
\hline Middle & $6 \pm 6(p \leq 0.001)(5)$ & $11 \pm 5(p \leq 0.001)(10)$ & $7 \pm 6(p \leq 0.001)(5)$ & $8 \pm 2$ \\
\hline Fourth & $6 \pm 6(5)$ & $10 \pm 5(10)$ & $6 \pm 6(5)$ & $7 \pm 2$ \\
\hline Last $^{*}$ & $48 \pm 25(p \leq 0.90)(50)$ & $17 \pm 14(p \leq 0.24)(10)$ & $49 \pm 28(p \leq 0.27)(50)$ & $38 \pm 22$ \\
\hline
\end{tabular}

Five-author paper (middle author as the corresponding author) ${ }^{b}$

\begin{tabular}{lllll}
\hline First & $31 \pm 15(p \leq 0.51)(30)$ & $44 \pm 17(p \leq 0.51)(40)$ & $28 \pm 17(p \leq 0.67)(20)$ & $34 \pm 9$ \\
\hline Second & $10 \pm 7(p \leq 0.69)(10)$ & $16 \pm 7(p \leq 0.55)(15)$ & $12 \pm 13(p \leq 0.10)(10)$ & $13 \pm 3$ \\
\hline Middle $^{*}$ & $34 \pm 20(p \leq 0.001)(30)$ & $20 \pm 10(p \leq 0.001)(20)$ & $33 \pm 20(p \leq 0.001)(30)$ & $29 \pm 8$ \\
\hline Fourth & $7 \pm 9(p \leq 0.59)(5)$ & $9 \pm 7(p \leq 0.91)(10)$ & $8 \pm 7(p \leq 0.11)(10)$ & $8 \pm 1$ \\
\hline Last & $18 \pm 18(p \leq 0.001)(10)$ & $11 \pm 9(p \leq 0.001)(10)$ & $19 \pm 19(p \leq 0.001)(10)$ & $16 \pm 4$ \\
\hline
\end{tabular}

Perceived credit mean percentage plus standard deviation and (median) per author by their byline position on a hypothetical manuscript, divided into separate categories of contribution. $P$-values reported in parentheses. ${ }^{a}$ Compared with the three-

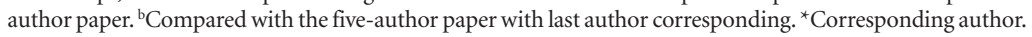

Of the 142 promotion committee representatives to whom we mailed the survey, $87(61 \%)$ responded. The response rate from medical schools in the USA $(66 \%)$ was significantly higher than the response rate from medical schools in Canada and Puerto Rico (28\%). Question completion rates-excluding questions with fill-in formats-ranged from $100 \%(87 / 87)$ to $83 \%(72 / 87)$.

$\mathrm{O}$ verall, respondents felt that the first author in a three-person byline had made the greatest contribution to the work performed (57\%), whereas the last author deserved most credit for both the initial conception (49\%) and supervision (54\%) of the project (Table 1). There was no significant difference in three-author compared with five-author bylines for the credit apportioned to the last author for initial conception, work performed or supervision (Table 1). By contrast, the first author's relative contributions decreased significantly for initial conception-from $37 \%$ to $29 \%$ - and for work performed- $57 \%$ to $46 \%$-but not for supervision. When comparing three-author and five-author bylines, the first author's overall perceived contribution decreased from $42 \%$ to $34 \%$, whereas the middle author's decreased from $17 \%$ to $8 \%$.

\section{... there are different ways of becoming an author on a scientific publication, and not all authors are viewed as equal contributors}

When a five-author byline with the last author designated as corresponding author was changed to a five-author byline with the middle (third) author designated as corresponding author, the middle author received increased credit for initial conception $34 \%$ versus $6 \%$ ), work performed $(20 \%$ versus $11 \%$ ) and supervision (33\% versus $7 \%$ ), and the last author's overall credit decreased from $38 \%$ to $16 \%$ (Table 1 ). 


\section{... readers [...] implicitly apportion authorship credit and frequently do so in the absence of any well-defined standards}

In addition, we also asked respondents for their perception of general trends and attitudes towards authorship of scientific publications. Forty per cent of the respondents (35/87), for example, agreed that granting authorship to someone who does not meet journal authorship criteria was a common occurrence. Half of the respondents also agreed that author inflation makes it significantly harder to judge whether or not a candidate merits promotion. Twenty-two per cent (18/82) affirmed that their promotion committee had a policy regarding the role of authorship order for evaluating candidates for academic promotion-14 out of these 18 respondents said that first, senior or corresponding author positions were preferentially weighted. The remaining four respondents noted that applicants were provided the opportunity to specify their contributions to publications.

A dding authors to a publication apparently does not affect the relative overall credit afforded to the last author, but the perceived contributions of all other authors suffer a drop in value. Although first and last authors received the largest amount of credit compared with middle authors in all three categories surveyed, the perceived contribution of the first and middle authors decreased in a five-person byline compared with a three-person one. This is consistent with previous studies of general medical publications (Davies et al, 1996; Shapiro et al, 1994), but differs from radiology publications, in which credit decreases the later an author appears in the byline (Sloan, 1996). Our finding that the last author, as corresponding author, suffered almost no loss of credit as the total number of authors increased suggests that disincentives to add more authors to the byline would probably be indirect-that is, displeasing their co-authors-rather than direct.

Respondents reduced last-author credit when the corresponding author was the middle author. This suggests that candidates for promotion or tenure would be well advised to highlight publications on which they acted as corresponding author, especially if they were not the last author.
Our observation that the credit apportioned to an author decreased the later an author appeared in the byline-except for the last author-is also consistent with previous findings about the determination of author order (Mowatt et al, 2002) showing that 'gift' authors most frequently appear towards the end of the author list (Bates et al, 2004). These findings suggest that some of the recent efforts to develop bibliometric formulae to measure author impact (Ball, 2005; Gomez-Alonso, 2004) would need to take into account both the number of authors on a paper and their position in the byline to be accurate.

\section{... all authors will benefit from a better and more quantitative understanding of how their contributions are likely to be perceived by their peers}

The actual contribution of a co-author can differ greatly from the contribution perceived from their byline position. More than 25 years ago, a survey among members of the American Psychological Association (Washington, DC, USA) found that 28\% of the respondents reported having been involved in a situation where they believed that their authorship was not commensurate with their input; $21 \%$ considered honorary authorship reasonable (Vasta, 1981). Our finding that $40 \%$ of respondents believed that the inappropriate granting of authorship is common suggests that little has changed. Although a more widespread use of author contribution statements might help, the vast majority of medical journals do not require such statements at present.

t should be emphasized that this survey was designed to measure perceptions of relative, not absolute, contributions to a paper. Because different scientific cultures and disciplines influence the perception of the relative importance of author byline position, our results are most pertinent to North American biomedical publications and faculties. As the questionnaire was in English, this might explain the lower response rates from Canadian and Puerto Rican medical schools, where the French and Spanish languages are prominent, and therefore our results might be less applicable to medical schools outside the USA. Although our results are most relevant to the biomedical literature, the trend of an increasing number of authors per academic paper is not restricted to this field. It is reasonable to presume that this trend, and its effect on perceived author contribution, is present in other research disciplines and that quantifying it will reveal the general, underlying economics of the labour structure of a publication. Scientists ultimately determine the academic value of each byline position and, consequently, it is economics that determines how much effort a contributing author will be willing to trade for a place in the byline. Although none of our respondents suggested additional categories for authorship credit, a potential limitation of our survey is that promotion committees might use more categories of potential credit than the three that we surveyed.

As bibliometric data can be easily obtained and quantified, it has an important role in decision-making-not only for academic promotion committees, but also increasingly for policy making. The bibliometric community has, for some time, faced the problem of how to apportion fair credit to each author of a publication if no further information about an author's contribution is supplied. Most researchers learn to apportion credit by author position informally and nonquantitatively. Therefore we hope this study helps authors, editors and committee members in various research disciplines to have a more concrete understanding of how credit is perceived and how author inflation affects it.

Supplementary information is available at EMBO reports online (http://emboreports.org)

\section{ACKNOWLEDGEMENTS}

We thank Kristy Lundahl, Lauren F. Heilig and David M. Crockett for their work on this project.

\section{REFERENCES}

Ball P (2005) Index aims for fair ranking of scientists. Nature 436: 900

Bates T, Anic A, Marusic M, Marusic A (2004) Authorship criteria and disclosure of contributions: comparison of 3 general medical journals with different author contribution forms. JAMA 292: 86-88

Beasley BW, Wright SM (2003) Looking forward to promotion: characteristics of participants in the prospective study of promotion in academia. J Gen Intern Med 18: 705-710

Davies HD, Langley JM, Speert DP (1996) Rating authors' contributions to collaborative research: the PICNIC survey of university departments of pediatrics. Pediatric Investigators' Collaborative Network on Infections in Canada. CMA/ 155: 877-882

Drenth JP (1998) Multiple authorship: the contribution of senior authors. JAMA 280: 219-221 
Eastwood S, Derish P, Leash E, Ordway S (1996) Ethical issues in biomedical research: perceptions and practices of postdoctoral research fellows responding to a survey. Sci Eng Ethics 2: 89-114

Gomez-Alonso J (2004) Author! Author! JAMA 292: 1815

ICMJE (2006) Uniform Requirements for Manuscripts Submitted to Biomedical Journals. Philadelphia, PA, USA: International Committee of Medical Journal Editors. www.icmje.org

Kwok LS (2005) The White Bull effect: abusive coauthorship and publication parasitism. / Med Ethics 31: 554-556

Laurance WF (2006) Second thoughts on who goes where in author lists. Nature 442: 26

Lazar R (2004) Up for grabs_-authors are a dime a dozen: the problem of multiple authors. Acta Paediatr 93: 589-591

Mowatt G, Shirran L, Grimshaw JM, Rennie D, Flanagin A, Yank V, MacLennan G, Gotzsche PC, Bero LA (2002) Prevalence of honorary and ghost authorship in Cochrane reviews. JAMA 287: 2769-2771

Mussurakis S (1993) Coauthorship trends in the leading radiological journals. Acta Radio/ 34: 316-320

Shapiro DW, Wenger NS, Shapiro MF (1994) The contributions of authors to multiauthored biomedical research papers. JAMA 271: 438-442

Sloan RM (1996) Coauthors' contributions to major papers published in the AJR: frequency of undeserved coauthorship. AIR Am I Roentgeno 167: 571-579

Smith J (1994) Gift authorship: a poisoned chalice? BMJ 309: 1456-1457

Tarnow E (1999) The authorship list in science: junior physicists' perceptions of who appears and why. Sci Eng Ethics 5: 73-88
Tarnow E (2004a) Byline corruption can only be controlled by true stakeholders. MedGenMed 6: 10

Tarnow E (2004b) Coauthorship in pathology, a comparison with physics and a survey-generated and member-preferred authorship guideline. MedGenMed 6: 1-2

Thomas PA, Diener-West M, Canto MI, Martin DR, Post WS, Streiff MB (2004) Results of an academic promotion and career path survey of faculty at the Johns Hopkins University School of Medicine. Acad Med 79: 258-264 Tscharntke T, Hochberg ME, Rand TA, Resh VH, Krauss J (2007) Author sequence and credit for contributions in multiauthored publications. PLoS Biol 5: e18

Vasta R (1981) The matter of publication credit: a survey of APA members. Journal Supplement Abstract Service Catalog of Selected Documents in Psychology 11: 2-3

From top left: Jonathan D. Wren is at the Oklahoma Medical Research Foundation, Oklahoma City, Oklahoma, USA. Katarzyna Z. Kozak, is at the Department of Internal Medicine, Exempla Saint Joseph Hospital, Denver, Colorado, USA. Kathryn R. Johnson is at the Department of Dermatology, University of Colorado School of Medicine, Colorado, USA. Sara J. Deakyne is at the Department of Pediatrics, University of Colorado School of Medicine, Aurora, Colorado, USA. Lisa M. Schilling is at the Department of Medicine, University of Colorado, Aurora, Colorado, USA. Robert P. Dellavalle is at the Veterans Affairs Medical Center, University of Colorado, Denver, Colorado, USA.

E-mail: robert.dellavalle@uchsc.edu
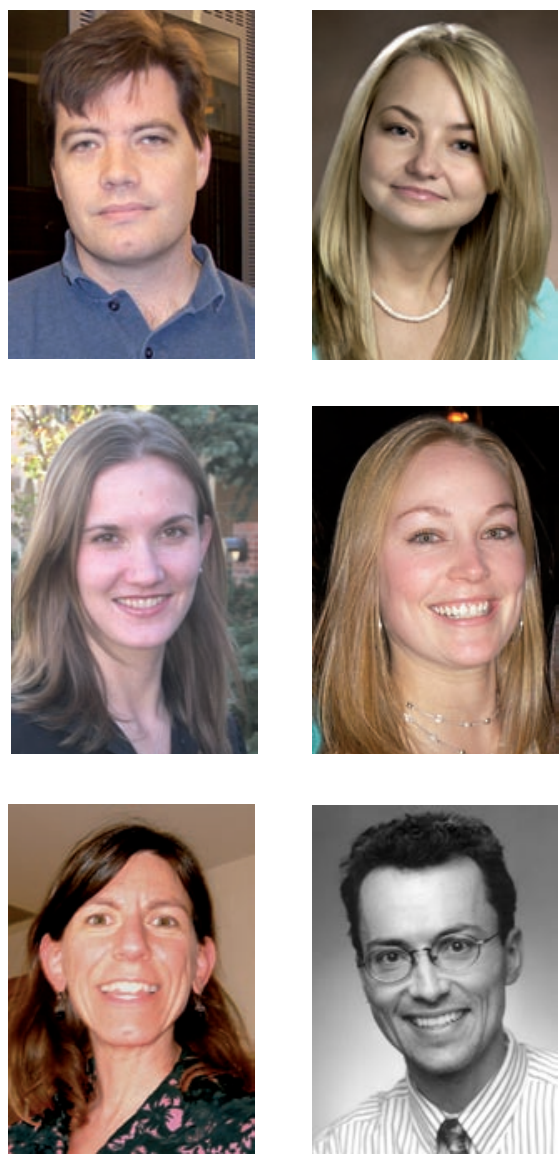

doi:10.1038/sj.embor.7401095 